\title{
INVESTIGAÇÃO EXPERIMENTAL ACERCA DA CINÉTICA DE REMOÇÃO DE RESÍDUOS DE SOLUÇÃO DETERGENTE ALCALINA EM PROTÓTIPO DE TROCADOR DE CALOR DE PLACAS
}

\author{
C. A. ALVARES ${ }^{1}$, P. P. GONÇALVES ${ }^{2}$, L. KUNIGK ${ }^{2}$, R. SISLIAN ${ }^{3}$ e R. GEDRAITE ${ }^{1}$ \\ ${ }^{1}$ Universidade Federal de Uberlândia, Faculdade de Engenharia Química \\ ${ }^{2}$ Centro Universitário do Instituto Mauá de Tecnologia, Departamento Engenharia Química e \\ Alimentos \\ ${ }^{3}$ Instituto Federal de São Paulo, Campus Guarulhos \\ E-mail para contato: claudia engquimica@hotmail.com
}

\begin{abstract}
RESUMO - Este artigo apresenta uma contribuição acerca da investigação experimental sobre a cinética de remoção de solução residual de detergente alcalino em protótipo de trocador de calor de placas. O estudo foi conduzido tendo por base o processo tradicionalmente empregado em sistemas de limpeza CIP da indústria. Foi estudada experimentalmente a cinética de remoção dos resíduos e feito o ajuste de modelo semi-empírico com base em função de transferência correspondente a sistema de primeira ordem com a presença de tempo morto (FOPDT, em inglês). Os resultados obtidos sugerem um bom ajuste do modelo matemático aos dados experimentais.
\end{abstract}

\section{INTRODUÇÃO}

A técnica de limpeza Clean-in-Place (CIP) é amplamente utilizada na indústria de alimentos e na indústria farmacêutica, dentre outras visando evitar a parada de produção e a desmontagem parcial ou total dos equipamentos de processamento. Sabe-se que diversas pesquisas têm sido realizadas nos últimos anos para procurar formas de melhorar o procedimento (Bansal, Chen (2006); Bremer et al (2006)). Tanto a tensão de cisalhamento aplicada quanto as reações químicas entre o fluido em escoamento e os depósitos formados são importantes na remoção de incrustações. A indústria de laticínios sofre de problemas específicos associados com a limpeza de equipamentos de processo, incluindo trocadores de calor (Georgiadis et al, 1998). Presentemente, o procedimento de limpeza envolve a lavagem do maquinário com solução detergente alcalina bastante concentrada, a fim de remover adequadamente os resíduos e incrustações que tendem a favorecer a contaminação. Depois de terminada esta etapa, é necessário o enxágue do equipamento para assegurar que o detergente residual presente no equipamento seja removido, evitando danos à saúde do consumidor final e perdas de qualidade do produto alimentício e/ou farmacêutico processado (Chen et al, 2004). 
Este trabalho apresenta uma contribuição ao tema, estudando o comportamento temporal da cinética de remoção de solução residual de detergente alcalino, na etapa de enxágue, em protótipo de trocador de calor de placas e ajustando modelo matemático semiempírico do tipo FOPDT aos dados experimentais.

\section{MATERIAIS E MÉTODOS}

Os experimentos foram conduzidos usando o sistema apresentado na Figura 1. Este consistiu de: (i)- um reservatório com capacidade para $100 \mathrm{~L}$, contendo solução de hidróxido de sódio a $0.5 \%$ em peso; (ii)- bomba centrífuga; (iii)- protótipo de trocador de calor de placas; (iv)- tubos de aço inoxidável 316 de 3/4" de diâmetro; (v)- sistema eletrônico de coleta de dados e (vi)- condutivímetro eletrônico microprocessado.

Primeiramente foram preparados $100 \mathrm{~L}$ de solução de detergente alcalino, composto por hidróxido de sódio e água potável, com concentração de $0,5 \%$ em peso. Esta solução foi armazenada no interior do tanque de alimentação principal. Na sequência, o sistema em estudo foi colocado em funcionamento, na temperatura ambiente, sendo feita a circulação de água potável para a estabilização das leituras do condutivímetro. Na sequência, esta água foi removida e armazenada e foi alimentada a solução de detergente alcalino, sendo esta feita circular em circuito fechado no interior do trocador de calor por aproximadamente 30 minutos, em circuito fechado. Finalizada a etapa anterior, foi providenciado o esgotamento da solução de detergente alcalino do interior do sistema, sendo este transferido para outro tanque independente. Quando o nível de detergente alcalino no interior do tanque principal de alimentação estava praticamente no fim, foi feita a alimentação de água potável no referido tanque, de modo a representar adequadamente o cenário tipicamente verificado em instalações industriais que empregam este tipo de limpeza. A água de enxágue alimentada era descartada após deixar o protótipo de trocador de calor, sendo antes medida em tempo real a respectiva condutividade. $\mathrm{O}$ processo de enxágue foi mantido até que a condutividade final atingisse o valor mínimo e praticamente não apresentasse variações significativas.

As variáveis de processo de interesse foram, as temperaturas terminais dos fluidos de processo envolvidos (água de aquecimento/resfriamento, solução de detergente alcalino e água de enxágue) e a condutividade da solução efluente do trocador de calor de placas. 
Figura 1 - Protótipo de trocador de calor de placas estudado

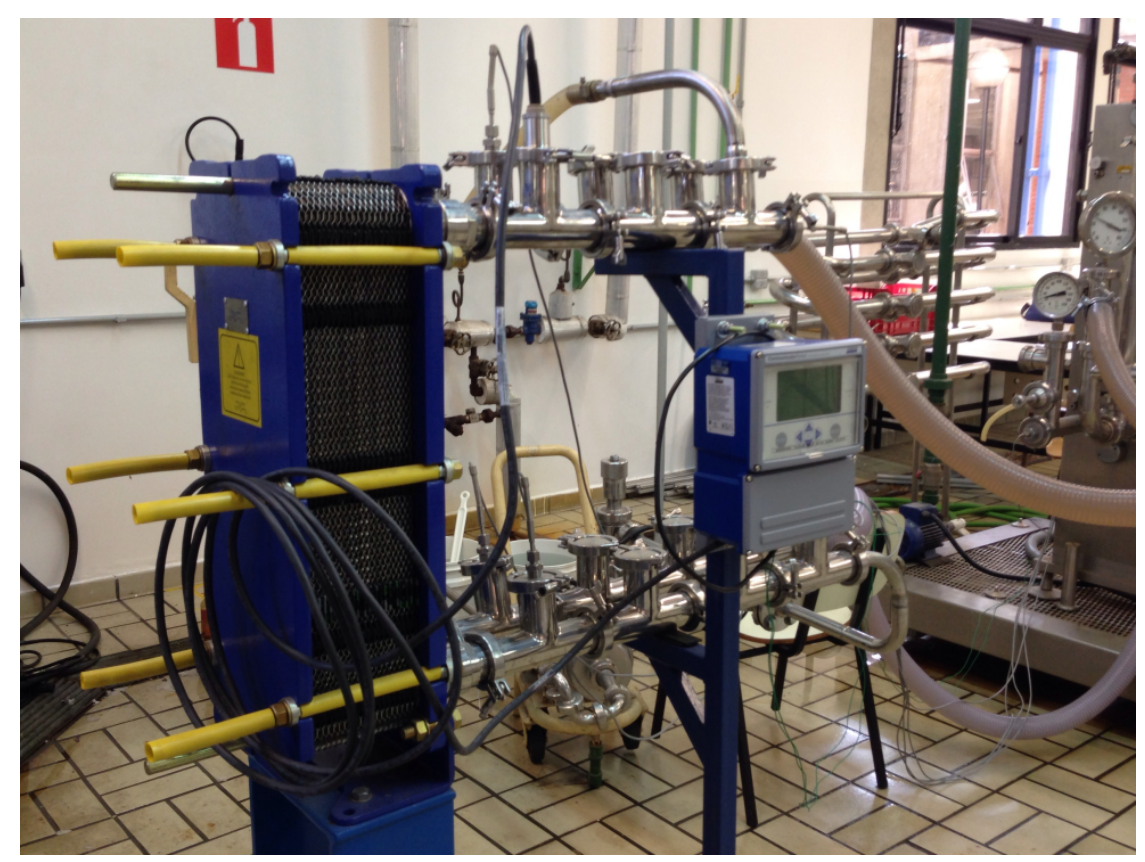

\section{RESULADOS E DISCUSSÃO}

O ensaio foi executado usando valor de vazão igual a $0,14 \mathrm{~L} / \mathrm{s}$, medida manualmente. Na Figura 2 são apresentados os resultados obtidos para a condutividade elétrica da solução efluente do trocador de calor de placas, medida experimentalmente.

Figura 2 - Comportamento temporal da condutividade medida na solução efluente

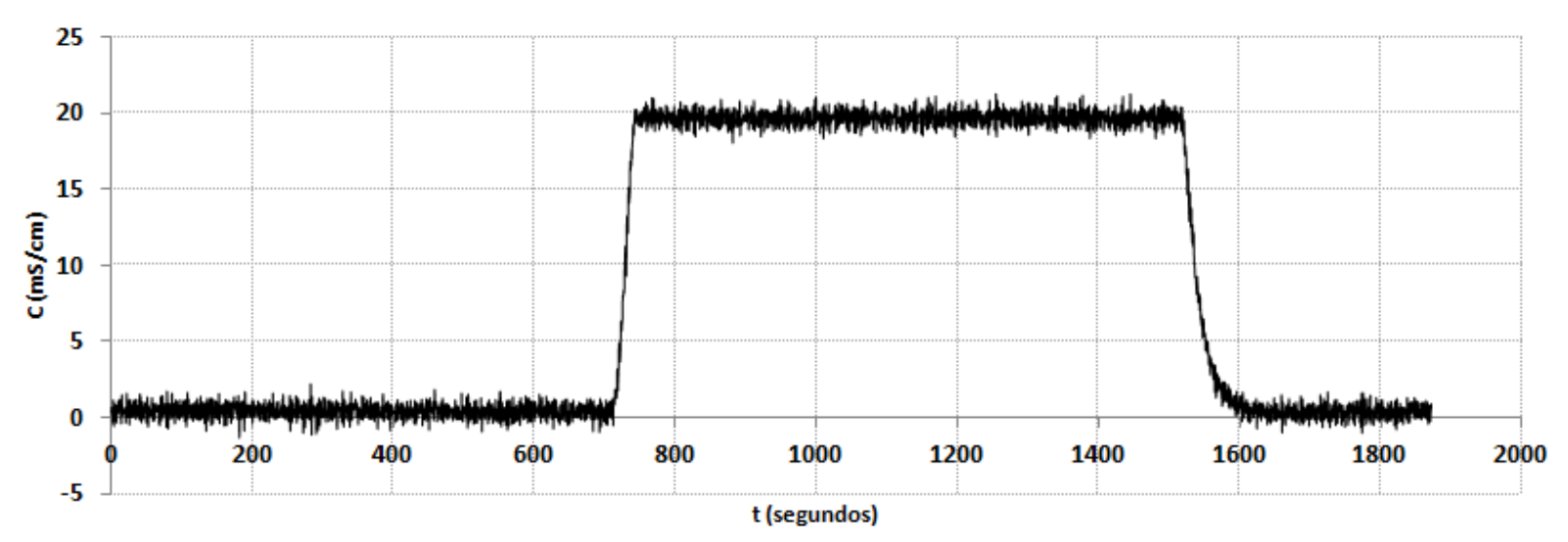


Com base nos resultados obtidos no experimento e apresentado na Figura 2, pode-se verificar que inicialmente, com a circulação de água potável o sistema estava em regime estacionário, com o valor médio da condutividade inicial igual a $0,46 \mathrm{mS} / \mathrm{cm}$. Aproximadamente no instante $\mathrm{t}=711$ segundos, a condutividade começa a aumentar, em resposta à alimentação da solução de detergente alcalino ao sistema em estudo. No instante $\mathrm{t}=$ 743 segundos, a condutividade atinge o valor máximo correspondente ao novo estado estacionário, igual a aproximadamente $19,7 \mathrm{mS} / \mathrm{cm}$. No instante aproximado $\mathrm{t}=$ 1.507 segundos, a condutividade começa a diminuir em resposta à alimentação de água de enxágue ao sistema, estabilizando em $0,39 \mathrm{mS} / \mathrm{cm}$. Os valores de condutividade medidos experimentalmente apresentaram certa variabilidade, em que pese o fato de ter sido feita a calibração do medidor antes de realizar o experimento, seguindo a recomendação do fabricante do condutivímetro. Contudo, este comportamento não afetou de maneira significativa a interpretação dos resultados.

Considerando os resultados obtidos no experimento e apresentados na Figura 2, foi ajustado o modelo matemático do tipo FOPDT mostrado na Equação 1, considerando uma resposta à perturbação do tipo degrau na vazão de água de enxágue (Garcia, 2005). Deve ser ressaltado o fato de que foi considerado que a vazão de água de enxágue apresentou variação brusca em seu valor, similar a uma variação do tipo degrau, por ocasião da introdução da mesma no tanque principal de alimentação, de amplitude igual a 0,14 L/s. Adicionalmente, é importante salientar que foi estudado o comportamento da cinética de remoção da solução residual de detergente alcalino, correspondente à etapa de enxágue com água de lavagem, do instante $\mathrm{t}=1507$ segundos em diante.

$$
\frac{C(s)}{F(s)}=\frac{-136,47}{22 \hat{\mathrm{a}}^{\text {TM }} s+1} \hat{\mathrm{a}}^{\wedge \mathrm{TM}} e^{-14 \hat{\mathrm{a}}^{\mathrm{ATM}} s}\left(\frac{\frac{m S}{c m}}{\frac{L}{s}}\right)
$$

Resolvendo a Equação 1 e voltando para o domínio do tempo, obtém-se a Equação 2, apresentada na sequência.

$$
C(t)=19,7-19,31 \hat{\mathrm{a}}^{\text {тा }}\left(1-e^{\frac{-(t-14)}{22}}\right)\left(\frac{m S}{c m}\right)
$$

Com base nos dados coletados por ocasião do experimento, foi feita a validação experimental do modelo matemático semi-empírico proposto para a cinética de remoção de solução residual de detergente alcalino, na etapa de enxágue. Na Figura 3 são apresentados os comportamentos temporais da condutividade medida e simulada correspondentes a esta etapa. 


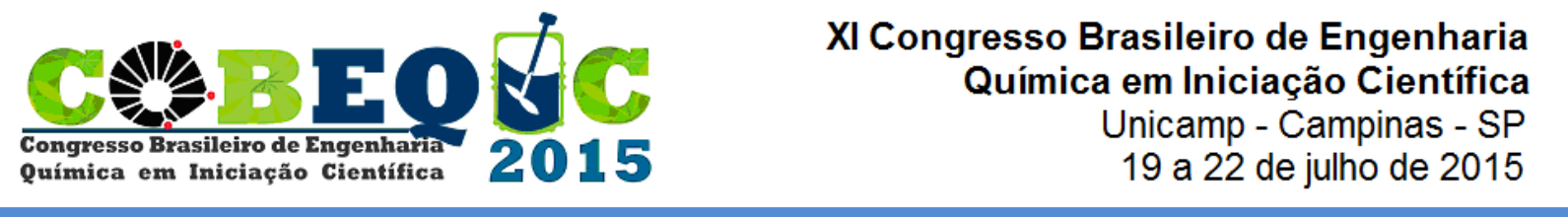

Figura 3 - Comportamento temporal da condutividade medida e simulada na solução efluente

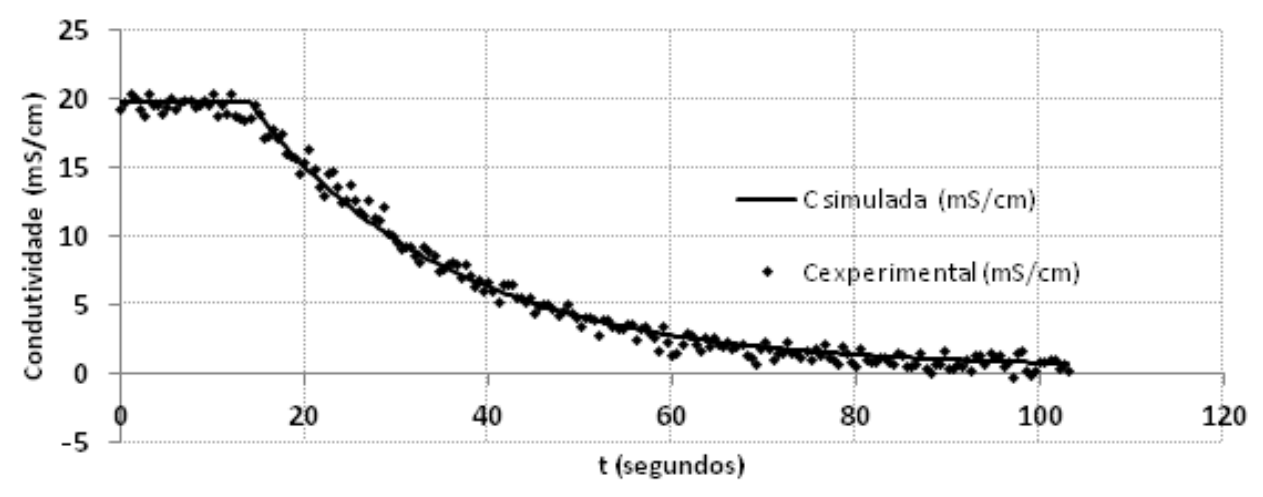

Considerando os resultados obtidos nos experimentos e na simulação apresentados na Figura 3, pode-se afirmar que o modelo ajustado representou a etapa inicial de decaimento da condutividade da solução efluente - que apresenta variação de amplitude muito pequena e lenta - por um tempo morto de aproximadamente 14 segundos. Após este primeiro período de tempo, o modelo proposto representou de maneira bastante coerente o comportamento da variação temporal da condutividade da solução efluente.

Deve ser enfatizado o fato de que a taxa de variação foi medida considerando-se como critério o tempo que o sistema demora em alcançar uma variação aproximada de $63,2 \%$ da variação total entre o valor da condutividade inicial e a condutividade final. Assim, foi verificado que o processo demorou aproximadamente 22 segundos para alcançar a variação imposta considerando a vazão de 0,14 L/s (Ogata, 2000).

\section{CONCLUSÕES}

Considerando os resultados obtidos no experimento e anteriormente apresentado, podese concluir que o modelo matemático semi-empirico proposto representou de maneira coerente e adequada o comportamento temporal do sistema.

Diante dos resultados apresentados, pode-se concluir que o modelo identificado da planta revela boa aderência com o comportamento experimental ensaiado, podendo ser usado como ferramenta de analise de processo. Com base neles, pode-se avaliar o impacto que alterações pré-estabelecidas no valor da vazão de água de enxágue apresentam sobre o tempo de operação e também sobre o volume total de água gasto em cada processo.

O principal beneficio que poderá resultar da aplicação do modelo no processo está relacionado ao menor tempo de processamento consumido nas etapas tipicamente empregadas em sistemas de limpeza CIP na indústria, especialmente na etapa de circulação de água de enxágue após a circulação do detergente alcalino.

Um ponto que deverá ser avaliado diz respeito ao consumo total de energia e de água no processo de limpeza CIP, o que não foi contemplado neste estudo. 


\section{AGRADECIMENTOS}

Os autores agradecem à UFU, ao IMT e à FAPEMIG (Fundação de Amparo à Pesquisa do Estado de Minas Gerais) pelos recursos concedidos e apoio em pesquisas nos projetos $\mathrm{N}^{\mathrm{o}}$ TEC-APQ-02100-12 (Estudo da Otimização de Sistema de Limpeza CIP).

\section{REFERÊNCIAS}

BANSAL, B., CHEN, X. D. 2006. A Critical Review of Milk Fouling in Heat Exchangers. Comprehensive Reviews in Food Science and Food Safety. Institute of Food Technologists. (5): $27-33$.

BREMER, P.J., FILLERY, S. \& McQUILLAN, A. J. Laboratory scale Clean-In-Place (CIP) studies on the effectiveness of different caustic and acid wash steps on the removal of dairy biofilms. 2006. International Journal of Food Microbiology. (106): 254 - 262.

CHEN, X. D., ÖZKAN, N., QIN, F., XIN, H. \& LIN, L. An Effective CIP Procedure for Removing Dairy Protein Based Deposit - A Laboratory Investigation. 2003 ECI Conference on Heat Exchanger Fouling and Cleaning: Fundamentals and Applications. New Mexico, USA.

GARCIA, C. Modelagem e Simulação de Processos Industriais e de Sistemas Dinâmicos. 2005. EDUSP, São Paulo.

GEORGIADIS, M. C., ROTSTEIN, G. E. \& MACCHIETTO, S. 1998. Modeling and Simulation of Shell and Tube Heat Exhangers under Milk Fouling. AIChe Journal. Vol. 44, No. 4: $959-971$.

GORMEZANO, L. 2007. Desenvolvimento e implementação de sistema para avaliar a cinética de remoção de resíduos presentes nos tubos de trocador de calor feixe tubular. Dissertação (Mestrado). São Caetano do Sul. Centro Universitário do Instituto Mauá de Tecnologia.

OGATA, K. Engenharia de Controle Moderno. Rio de Janeiro: Prentice Hall do Brasil, $3^{\text {a }}$ edição, 2000. 